\title{
2007/5
}

A two-sided matching model of monitored finance

\author{
Kaniska Dam
}




\title{
CORE DISCUSSION PAPER
}

$2007 / 5$

\section{A two-sided matching model of monitored finance}

\author{
Kaniska DAM ${ }^{1}$
}

January 2007

\begin{abstract}
We analyse a model of two-sided matching and incentive contracts where expert investors (venture capitalists) with different monitoring capacities are matched with firms with different levels of initial wealth. Firms do not have sufficient start-up capital to cover their project costs and hence, seek external financing. In equilibrium, the matching and the payoffs of the venture capitalists and the firms are determined simultaneously. More effective VCs and higher-wealth firms consume higher payoffs. We also show that, in equilibrium VCs with higher monitoring ability invest in firms with lower initial wealth following a negatively assortative matching pattern.
\end{abstract}

Keywords: venture capital, assortative matching, incentive contracts

JEL classification: C78, D82, E44, G24

${ }^{1}$ Centro de Investigacion y Docencia Economicas, México. E-mail: kaniska.dam@cide.edu

The author owes thanks to Jordi Caballé, Archishman Chakraborty, Maitreesh Ghatak, Inés MachoStadler, Jordi Masso, Enrico Minelli, Saltuk Ozerturk, David Pérez-Castrillo and Jonathan Wang for various helpful suggestions. Discussions with Patrick Legros and Javier Suarez in several occasions have significantly improved the paper. The current version also benefited from comments of the seminar participants at the FMA Annual Meeting (Chicago), the Midwest Finance Association Meeting (Chicago), Second Summer School on Heterogeneity (Louvain-la-Neuve), Baruch College (New York), CIDE (Mexico City), CIMAT (Guanajuato), El Colegio de México (Mexico City), University of Dundee (Dundee) and Sabanci University (Istanbul). The author gratefully acknowledges the financial supports from the project MEIF-CT-2004-501150 of the European Commission.

This paper presents research results of the Belgian Program on Interuniversity Poles of Attraction initiated by the Belgian State, Prime Minister's Office, Science Policy Programming. The scientific responsibility is assumed by the author. 


\section{Introduction}

During the last three decades, the US venture capital industry has witnessed a dramatic increase in the fund flowing into new ventures. In the decades 1960 and 70, although a significant number of pension funds invested in new start-up firms, little resources were devoted to monitoring and managing these investments. In the mid-1980's, the overwhelming increase in the supply of venture capital was mainly due to the entry of the gatekeepers (the investment advisors) into this industry. These advisors came up with high quality expertise in raising resources for investment in young firms and ability to manage these funds. They monitored the firms' performance closely and became integral parts of the ventures with respect to the decision making.

A typical venture organisation is characterised by limited partnerships, in which the venture capitalists (VCs, henceforth) are general partners who control the fund's activities. Apart from fund raising, these general investors monitor the firms performance and provide their managerial expertise in the management of the fund. Venture capitalists often differ in abilities to monitor, and are often ranked into top-tier, second-tier, ..., bottom-tier, etc. with respect to their monitoring capacities. In the context of investment banking this ranking is explicit. ${ }^{1}$ Although in the venture capital industry this ranking is not explicit, experience of an investor (number of previous investments made by him prior to a particular investment) can be taken as an empirical measure of monitoring ability (see Sorensen [25]). Differences in monitoring capacities are important since it is wellrecognised that better monitors are able to add more value to the ventures they invest in. Also, venture capitalists can differ with respect to their ability to attract funds which is often taken as a measure of their reputation.

In this paper, we analyse several aspects of venture capital industries, although the model presented here can address other types of financial institutions such as investment banking. First, the venture capitalists (who differed in expertise) have invested in special type of funds which might be distinguished according to better growth prospects, levels of riskiness, possibility of faster maturity before going public, etc. The investment outcomes typically depend on the characteristics of the firms and the VCs. More effective monitors are better positioned in the market in a sense that they have access to better investment opportunities. On the other hand, less wealth-contrained firms are more likely to succeed. Consequently, the market may observe sorting between firms and VCs. In this regard, we ask the following question: what kind of sorting pattern we observe when venture capitalists decide to invest in a new venture? Sorting is important since it influences the venture outcomes. In an empirical analysis of the US venture capital industry over 14 years, Sorensen [25] shows that the market outcomes significantly differ with and without sorting. Second, increase in the quality of expertise to manage fund resulted in immense growth prospect and faster maturity in the young start-ups. How one can explain this

\footnotetext{
${ }^{1}$ The investment banks ranked in the bulge bracket are characterised by higher monitoring abiity.
} 
gain in efficiency in the venture capital industry? This is particularly important regarding the nature of portfolio in venture funds, since from the second half of 1980, as opposed to the preceeding two decades, the flow of funds was accompanied by greater quality of expertise (following the emergence of the gatekeepers). Although many empirical studies address this question (see Gompers and Lerner [11]), a little theoretical works have been devoted in this respect. Third, we analyse the financial contracts one can observe in the VC-backed funds. This analysis is particularly interesting since, as postulated by Kaplan and Stromberg [14], venture capital contracting can approximate closely the contracts in the investor theory.

We consider a model of monitored finance where the market consists of venture capitalists with different abilities to monitor and entrepreneurs/firms with different levels of start-up capital. Analysis of possible sorting in venture capital industries calls for a two-sided matching model. A matching describes different possible VC-firm pairs. Each pair writes binding contracts which creates the value of a venture. This value is shared between the parties according to a rule which is imbedded in the terms of the contract. In the equilibrium, the payoffs to the venture capitalists and the firms and the matching are determined simultaneously. A contract specifies that the VC finances the project and receives state-contingent claims on the project return. Each firm operates on its project after it obtains fund and chooses a non-contractible effort level. Choice of effort influences the probability of having a high return from the project. Firm's liability is limited to its current income. Hence, differences in wealth imply differences in liabilities. This constraint generates moral hazard at the firm level. Monitoring by venture capitalist is aimed at ameliorating this moral hazard.

Monitored finance is a dominant form of financing young projects. One such example is the one we address here. In general, the role of the venture capitalists is a mix of fund management and investment. We have discussed earlier that venture capitalists, apart from raising funds from their client-pool, closely monitor the firms' progress and manage the fund's activities. Relationship banking is another form of monitored finance. Sometimes banks lock themselves into long term relationships with their borrowers (see Rajan [19]). Often sorting through endogenous matching is prevalent in investment banking (see Chen [6]). Also, literature on financial intermediation conclude that when external borrowing by firms is indispensable, capital-poor firms are denied credits by uninformed investors and they have to rely on the informed capital available in the economy (see Hölmstrom and Tirole [12], and Repullo and Suárez [20]). Informed capital owns, in general, better monitoring capacity compared to less informed investors. Hence, it is better able to cope with moral hazard at the firm level that arises because of the inability to contract upon all the actions taken by the entrepreneurs.

The two-sided matching game considered here is a one-to-one game. In a limited partnership venture organisation, covenants might oblige the general partners to invest in a limited number of venture funds. Investment in unlimited number of funds may lead 
to opportunistic behaviour and a venture capitalist can only dedicate little time in the management of a particular fund. Hence, in order to capture what this sort of covenants postulate, we restrict the investment of a venture capitalist in only one firm. ${ }^{2}$ In this matching game, we determine the equilibrium matching and payoffs (arising from the contracts) simultaneously. An outcome of this market is a matching function and a set of feasible payoffs compatible with the matching. We use stability as the equilibrium concept. An outcome is stable (or, is in equilibrium) if there is no VC-firm pair that would be (strictly) better-off by signing a different contract.

We analyse the equilibrium of this market. The equilibrium payoffs and matching are determined simultaneously. We consider a matching game where venture capitalists and firms interact for one period. We show that in the equilibrium matching, VCs with better capacity to monitor invest in firms with lower wealth (negatively assortative matching). The nature of substitutability between the effectiveness of monitoring and the wealth of the firms guarantee this kind of monotone matching pattern under moral hazard. Becker [3], Shimer and Smith [24], and Legros and Newman [15] give sufficient conditions for assortative matching. These conditions involve substitutability between the characteristics of the matched individuals. When the contracts between venture capitalist and firm involve provision of incentive, the optimality of contracts is not implied by the total surplus maximisation. In the current model, as in Legros and Newman [15], the substitutability in producing as well as in transferring the surplus determines the negatively assortative equilibrium matching pattern.

Several other works consider the presence of two-sided matching in the determination of contracts between principals and agents. Dam and Pérez-Castrillo[8] analyse a pricipal-agent matching market with one-sided heterogeneity. Besley and Ghatak [4] analyse a principal-agent matching model in the presence of motivated agents in organisations. Ackerberg and Botticini [1], and Li and Ueda [16] test empirical models to show the existence of endogenous matching as determinant of contract forms in the contexts of the markets for landlord-tenants and CEO-firms, respectively. Serfes [22] determines assortative matching pattern between risk-sharing and incentive when landlords and tenants are matched. The last two papers address theoretical issues in matching in principal-agent set-up. They ask the question that given the characteristics of principals and agents, and given a set of optimal contracts between them, how should the equilibrium matching pattern look like. They employ the two-sided matching similar to the college admission problem developed by Roth and Sotomayor [21]. Unlike these works, we analyse simultaneous determination of matching and contracts (as well as payoffs) in equilibrium. In this sense the current model can be viewed as a generalisation of the assignment game of Shapley and Shubik [23] in which the equilibrium matching is determined along with payoffs of buyers and sellers, rather than taking the payoffs to a pair as given. Sorensen [25] analyses an empirical two-sided model of venture capital similar to that of Roth and

\footnotetext{
${ }^{2}$ To analyse the case where a venture capitalist may invest in many but limited number of funds, a one-to-many matching model can be considered. This will be a trivial extension of the current model.
} 
Sotomayor [21] and show the influence of assortative matching.

There are other works which analyse matching between venture capitalists and firms where the individuals in a market are matched according to a random matching function. Michelacci and Suárez [17] consider a random matching model where venture capitalists differ in abilities and analyse the relation between monitoring ability and new business creation. They show that the faster the young ventures mature and go public, the quicker the venture capitalists' informed capital is redirected towards the new start-ups. Inderst and Müller [13] develop a model of contracting, bargaining and search to show that the relative scarcity of venture capital affects the pricing, contracting and value creation in start-ups. Both these models, unlike ours, are based on random matching, search and bargaining approach. In our view, a reasonable matching among individuals should rather be treated as endogenous. Our model considers a centralised market where individuals are matched according to a matching function. A decentralised mechanism is considered in Dam and Pérez-Castrillo [8]. The empirical work of Sorensen [25] also supports the view presented in the current work.

The paper is organised as follows. In Section 2, we lay out the basic model. In the following section, we ananlyse optimal contract for a particular VC-firm pair. We describe the matching market in Section 4. In Section 5, we state the main results concerning equilibrium. In the next section, we analyse the effects of entry of new venture capitalists on the equilibrium outcomes. We conclude in Section 7. A formal analysis of the set of stable outcomes and relevant proofs are relegated to the Appendix.

\section{The Model}

We consider a financial market where there is a set $F=\left\{f_{1}, \ldots, f_{n}\right\}$ of $(n \geq 2)$ riskneutral firms. Firm $f_{j}$ is endowed with initial wealth $w^{j}$, firm $f_{j^{\prime}}$ has wealth $w^{j^{\prime}}$, etc. Each firm has an innovative project whose implementation costs 1 monetary unit. We arrange firms according to their wealth levels in descending order as $w^{1} \geq \ldots \geq w^{n} \geq$ 0 . Firm's initial wealth is not sufficient to cover the entire project cost, hence each firm seeks external finance. There is also a set $V=\left\{v_{1}, \ldots, v_{N}\right\}$ of $(N \geq 2)$ riskneutral venture capitalists (who are potential investors) enowed with different monitoring capacities $m=\left(m_{1}, \ldots, m_{N}\right)$. We arrange the venture capitalists with respect to their monitoring capacities in descending order as $m_{1} \geq \ldots \geq m_{N}>0$.

Venture capitalists and firms are matched in pairs. Whenever matched, a VC-firm pair signs a contract and the VC finances the entire project. ${ }^{3}$ We assume that a VC can invest in at most one venture fund due to possible technological rigidities, organisational covenants, etc. A dollar invested in a venture yields a random return $y$ in the event

\footnotetext{
${ }^{3}$ There is no loss of generality if we assume that the entire project is financed by the VC since firm's wealth is observable.
} 
of success with probability $e$ and nothing in case of failure, and private benefits $B$ to the firm. The probability of success is determined by firm's non-contractible effort level $e \in[0,1]$. In order to gain more private benefits the firm has to divert resources from the venture which gives rise to moral hazard problem at the firm level. Monitoring by venture capitalists is meant to ameliorate the moral hazard. The idea is that, if a firm is monitored with higher effectiveness its benefits from shirking are reduced. Thus we consider private benefits of the form:

$$
B\left(e, m_{i}\right)=\frac{1-e^{2}}{2 m_{i}}
$$

The above functional form implies that a more effective monitor can impose a higher non-pecuniary cost on the private benefit, thereby making it less attractive and making the firm behave more diligently. ${ }^{4}$

\section{Contract between a Firm and a VC}

A VC-firm pair $\left(v_{i}, f_{j}\right)$ signs a contract $c_{i j}=\left(R_{i j}, r_{i j}\right)$ that specifies state-contingent payments to the $\mathrm{VC}, R_{i j}$, in case of success and $r_{i j}$, in the event of failure. The corresponding probability of success chosen is $e_{i j}$. The expected utilities of venture capitalist $v_{i}$ and firm $f_{j}$ when they sign the contract $c_{i j}$ are, respectively:

$$
\begin{aligned}
U_{i}\left(f_{j}, c_{i j}\right) & =e_{i j} R_{i j}+\left(1-e_{i j}\right) r_{i j}-m_{i}, \\
u_{j}\left(v_{i}, c_{i j}\right) & =e_{i j}\left(y-R_{i j}\right)-\left(1-e_{i j}\right) r_{i j}+\frac{1-e_{i j}^{2}}{2 m_{i}} .
\end{aligned}
$$

The choice of effort is not contractible. Let $e_{i j}$ maximise the firm's utility, i.e.,

$$
e_{i j} \in \underset{e}{\operatorname{argmax}}\left\{e\left(y-R_{i j}\right)-(1-e) r_{i j}+\frac{1-e^{2}}{2 m_{i}}\right\} .
$$

This is the incentive compatibility constraint of firm $f_{j}$. We denote by $c^{\text {null }}$, the null contract, under which all individuals consume zero utility. Suppose, firm $f_{j}$ 's reservation payoff is $s^{j} \geq 0$. A venture capitalist faces a risk-free market rate of interest which is normalised to zero. Venture capitalist's and firm's individual rationality are given by the following constraints:

$$
\begin{aligned}
e_{i j} R_{i j}+\left(1-e_{i j}\right) r_{i j} & \geq 0 \\
e_{i j}\left(y-R_{i j}\right)-\left(1-e_{i j}\right) r_{i j}+\frac{1-e_{i j}^{2}}{2 m_{i}} & \geq s^{j} .
\end{aligned}
$$

\footnotetext{
${ }^{4}$ Another interpretation of $m_{i}$ may be the quality of the VC $v_{i}$. Under a better VC, a firm's increase in effort entails lower sacrifice of private benefit.
} 
Firm's liability is limited to the state-contingent return plus its initial wealth. Limited liability implies:

$$
\begin{aligned}
R_{i j} & \leq y+w^{j} \\
r_{i j} & \leq w^{j}
\end{aligned}
$$

The assumption of risk neutrality together with limited liability makes the incentive compatibility constraint costly and hence, it gives rise to moral hazard at the firm level. Since firm's utility is (strictly) concave in $e$, one can replace $\left(I C_{j}\right)$ by the first order condition of the firm's maximisation problem as follows:

$$
e_{i j}=m_{i}\left(y-R_{i j}+r_{i j}\right)
$$

A contract for a VC-firm pair must satisfy the individual rationality and limited liability constraints. We club all these natural restrictions into the following definition.

Definition 1 A contract is feasible for a firm $f_{j}$ if it satisfies the restrictions of individual rationality and limited liability.

Denote by $X^{j}$ the set of contracts that are feasible for firm $f_{j}$. From now on we will concentrate only on feasible contracts. Let $Z^{j}$ be the subset of feasible contracts that are incentive compatible. Consider the following programme.

$$
\max _{c_{i j} \in Z^{j}} U_{i}\left(f_{j}, c_{i j}\right)
$$

Let $c_{i j}\left(s^{j}\right)$ be the set of contracts that solve the above maximisation programme. ${ }^{5}$ One basic characteristic of these contracts are that they are (constrained) Pareto optimal. Let $U\left(m_{i}, w^{j}, s^{j}\right)$ and $u\left(m_{i}, w^{j}, s^{j}\right)$ be the payoffs to $\mathrm{VC} v_{i}$ and firm $f_{j}$, respectively, generated by $c_{i j}\left(s^{j}\right)$. These payoffs correspond to a point of a concave utility possibility frontier.

The above is a classic example of the set of contracts often discussed in the principalagent literature when only a given principal-agent relationship is concerned. In other words, this is the set of feasible and incentive compatible contracts when one abstracts from a principal-agent market, and focuses only on a particular (given) relationship. The payoff to the firm is determined entirely by its outside option, and hence exogenous. As we have mentioned earlier that one of the main goals of this paper is to endogenise the reservation utilities (hence, the payoffs) of the firms, in the following sections, we concentrate on a market where many venture capitalists and firms interact, and consequently the payoff of each firm is determined endogenously and influenced by the other VC-firm pairs formed in the market.

\footnotetext{
${ }^{5}$ In Appendix we analyse the optimal contracts in details.
} 


\section{Matching}

In the previous section we have described the optimal contract between one firm and one venture capitalist. In a market comprising of several firms and VCs, the same contracts may not arise in equilibrium since contract signed by a particular pair imposes externalities on the (optimal) contracts for the other pairs. To this end, a partial equilibrium model of VC-firm contracting (the one described in the previous section) is somewhat inadequate to characterise the market equilibrium. In this section we assume that firms and VCs are matched according to a matching function. When the pair is formed, and a contract is signed. A contract for a matched pair is influenced by the other pairs being formed according to the matching function. On the other hand, a firm can seek for alternative financier. This implies that the matching depends on the contract terms. In the model of the previous section, given a particular VC-firm pair, the payoff of the firm is completely determined by its (exogenously given) reservation utility. When several VCs and firms are considered, the reservation utility of firms become endogenous. Hence, in this market the matching and the payoffs generated from the contracts (which constitute an outcome) are endogenous too.

In this section we would like to determine the payoffs of all VCs and firms as well as the optimal matching. Simultaneous determination of matching and payoffs calls for defining a relevant outcome for the market. In this model an outcome consists of a matching rule and a corresponding vector of feasible payoffs.

Definition 2 A matching for the market is a mapping $\mu$ that assigns a VC (a firm) to a firm (a VC) (we write $\mu\left(v_{i}\right)=f_{j}\left(\mu\left(f_{j}\right)=v_{i}\right)$ ), or specifies that a $V C$ (a firm) stays alone (we write $\mu\left(v_{i}\right)=v_{i}\left(\mu\left(f_{j}\right)=f_{j}\right)$ ). A one-to-one matching is a mapping $\mu$ such that $\mu\left(v_{i}\right)=f_{j}$ if and only if $\mu\left(f_{j}\right)=v_{i}$.

A matching function assigns a firm to a venture capitalist or vice versa. It also allows for the fact that an individual may stay unmatched. The last part implies the restriction to a one-to-one matching. We have discussed earlier that covenants may put limits to the number of firms the venture capitalists invest in. Hence, we assume that a $\mathrm{VC}$ can invest only in one firm, or a firm can be financed at most by one VC.

A menu of contracts compatible with a matching $\mu$ is a vector of feasible contracts, one for each pair matched according to $\mu$. Each of these feasible contracts generates feasible payoffs $U_{i}$ for $\mathrm{VC} v_{i}$ and $u_{j}$ for firm $f_{j}$ compatible with this particular matching. Let the sets of feasible payoffs to the VCs and the firms be $U=\left(U_{1}, \ldots, U_{N}\right)$ and $u=\left(u_{1}, \ldots, u_{n}\right)$.

Definition 3 An outcome $(\mu, U, u)$ is a matching $\mu$ and feasible payoffs compatible with the matching. 
The outcomes of the market we describe here are determined endogenously. This endogeneity has two aspects. First, the contracts signed by the VCs and the firms, as well as their payoffs are endogenous. The second aspect is that the matching itself is endogenous. In the following section we determine the set of equilibrium payoffs for the market as well as which firms are financed by which venture capitalists (the matching pattern). We require that a reasonable outcome should be immune to the possibility of being blocked by any VC-firm pair (as well as by any single individual). In other words, an outcome for a market has to be stable.

Definition 4 An outcome ( $\mu, U, u)$ for the market is stable (or, is in equilibrum) if there is no pair $\left(v_{i}, f_{j}\right)$ and no payoff configuration $\left(U^{\prime}, u^{\prime}\right)$ generated by a feasible contract $c_{i j}^{\prime}$ such that $U_{i}^{\prime}>U_{i}$ and $u_{j}^{\prime}>u_{j}$.

The above definition implies that no VC-firm pair with a feasible contract can block an outcome if it is stable. The restriction of individual rationality implies that no individual firm or VC unilaterally blocks a stable outcome.

\section{The Set of Stable Outcomes}

In this section we describe the set of stable outcomes of the market. First, all contracts in a stable outcome are (constrained) Pareto optimal. By optimality we mean that there is no possibility of (strictly) improving upon the payoff of any individual in a VC-firm pair without making the other worse-off.

Proposition 1 All contracts in a stable outcome are optimal.

It is worth noting that the optimality of a contract between a venture capitalist and a firm in any stable outcome is guaranteed by the possibility that the same pair can block the initial outcome with a different feasible contract. Hence, a contract signed by a matched pair $\left(v_{i}, f_{j}\right)$ must maximise the expected utility of one party, taking into account that the other gets at least a certain utility level. The optimality of the contracts in a stable outcome implies that the set of payoffs generated by solving programme $\left(P_{i j}\right)$ form a part of the stable outcome. This makes sure that if in a stable outcome if a firm $f_{j}$ is matched with $\mathrm{VC} v_{i}$, then $U_{i}=U\left(m_{i}, w^{j}, s^{j}\right)$ and $u_{j}=u\left(m_{i}, w^{j}, s^{j}\right)$.

Proposition 2 In a stable outcome,

(a) the higher the wealth of a firm, the higher is its payoff;

(b) an unmatched firm or VC consumes zero payoff.

The above proposition is fairly intuitive. If a firm with higher wealth gets lower payoff then the $\mathrm{VC}$ who is matched with the firm with lower wealth can always offer a slightly 
better contract to the wealthier firm and form a blocking pair. This property depends neither on the number of firms and venture capitalists in the market, nor on a specific matching pattern. If all firms had same initial wealth, they would have obtained same payoffs.

Proposition 3 The number of pairs formed is the number of individuals in the short-side of the market. Only the wealthiest firms and the most effective monitors are matched.

Given the restriction to one-to-one matching, it is clear that if there are different numbers of VCs and firms everybody cannot be matched. If the firms form the short-side of the market $(n<N)$, then only $n$ pairs are formed. All firms and the $n$ most effective monitors are matched. On the other hand, if firms constitute the long-side of the market $(n>N)$, only $N$ pairs are formed, all VCs and the wealthiest $N$ firms are matched. Clearly, if there are equal number of firms and VCs, everybody is matched. In this sense, the equilibrium matching is optimal since only the venture capitalists with highest monitoring capacity and the wealthiest firms form pairs, and total value of all the ventures is maximised. In the following definition we introduce the concept of willingness to pay.

Definition 5 The willingness to pay of a venture capitalist $v$ for $w$ against $w^{\prime}$ is defined as

$$
\Delta U_{i}\left(f_{j}, f_{j^{\prime}}\right) \equiv U\left(m_{i}, w^{j}, s^{j}\right)-U\left(m_{i}, w^{j^{\prime}}, s^{j^{\prime}}\right) .
$$

The above expression reads as: for given levels of initial wealth, $w^{j}$ and $w^{j^{\prime}}$, if venture capitalist $v_{i}$ is currently engaged with $f_{j^{\prime}}$, the above quantity is the maximum additional amount he is willing to pay to contract with $f_{j}$ instead, or this is the maximum extra amount he is willing to pay to keep $f_{j}$ in case he is currently with this firm rather than $f_{j^{\prime}}$.

Proposition 4 In a stable outcome venture capitalists with higher monitoring capacity invest in firms with lower wealth, i.e., the matching is negatively assortative.

In the above proposition we describe the equilibrium matching pattern. We show that firms with higher wealth obtain credit from VCs with lower capacity of monitoring, i.e., the matching is negatively assortative. In order to prove the above property, we proceed as follows. First, we show that the willingness to pay for a wealthier firm is decreasing in monitoring capacity. When contracts require provision of incentives, firms' wealth and monitoring capacity are substitutes. Due to limited liability, moral hazard is more severe with a more wealth constrained firms, and hence the values of these ventures increase with more effective monitoring. This substitutability is equivalent to the condition of decreasing willingness to pay. Then we show that decreasing willingness to pay is a sufficient condition for negatively assortative matching. If in a stable outcome willingness to pay decreases but the matching is not NAM then there will be at least one blocking pair. 
We have mentioned earlier that the reservation utilities of firms, and hence the payoffs are determined simultaneously and they are endogenous. We have also stated in Proposition 3 that in a stable outcome wealthier firms get higher payoffs. Since, in a stable outcome the payoffs depends on the reservation utilities (in fact, $u_{j}=s^{j}$ ), from this proposition it is clear that firms' reservation payoffs are not exogenous. Given the negatively assortative matching pattern, one can say more regarding the endogenous determination of the payoffs.

Proposition 5 Suppose in a stable outcome $l=\min \{n, N\}$ pairs are formed. Then this stable outcome exhibits the following property:

$$
\Delta U_{l-j+1}\left(f_{j}, f_{j+1}\right) \geq s^{j}-s^{j+1} \geq \Delta U_{l-j}\left(f_{j}, f_{j+1}\right), \text { for all } j=1, \ldots, l-1 .
$$

From Propositions 3 and 5, it is clear that the reservation utilities of the firms are endogenous. These are determined from a set of inequalities described in the aforesaid propositions. Consequently, the payoffs of the VCs and the firms are also endogenous since they depend on the values of reservation utilities of the firms. The equilibrium payoff of each firm is bounded below and above. Let $\underline{u}=\left(\underline{u}_{1}, \ldots, \underline{u}_{n}\right)$ and $\bar{u}=\left(\bar{u}_{1}, \ldots, \bar{u}_{n}\right)$ be the minimum and maximum payoffs of the firms, respectively. To see the existence of a minimum and a maximum, consider two firms with different wealth levels. If the venture capitalist investing in a firm is willing to contract with a firm with higher wealth, the maximum amount he is willing to give up equals his willingness to pay for the wealthier firm. Hence, at equilibrium the minimum the wealthier firm can obtain is the payoff of the firm with lower wealth plus the aforesaid amount. On the other hand, the maximum the the firm with higher wealth can obtain is the payoff of the firm with lower wealth plus the willingness to pay of the monitor investing in the wealthier firm. It is also the case that the equilibrium payoff to each $\mathrm{VC}$ is bounded below and above. In a similar fashion as above, let $\underline{U}=\left(\underline{U}_{1}, \ldots, \underline{U}_{N}\right)$ and $\bar{U}=\left(\bar{U}_{1}, \ldots, \bar{U}_{N}\right)$ be the minimum and maximum payoffs of the $\mathrm{VCs}$, respectively.

Finally, it is worth noting that a stable outcome $(\mu, U, u)$ is not unique. This is because the (equilibrium) reservation utility of a firm $f_{j}$ is not unique, and may range over an interval. Further, if one stable outcome $(\mu, U, u)$ is better for a firm than another stable outcome $\left(\mu^{\prime}, U^{\prime}, u^{\prime}\right)$, then $(\mu, U, u)$ is better than $\left(\mu^{\prime}, U^{\prime}, u^{\prime}\right)$ for all the matched firms and and worse for all the matched VCs. In particular, corresponding to an optimal matching $\mu$, there is an outcome $(\mu, \bar{U}, \underline{u})$ which is the best from the VCs' point of view and worst for the firms. This outcome can be called the $V$-optimal stable outcome. On the other hand, there is a stable outcome $(\mu, \underline{U}, \bar{u})$ which is the best from the firms' point of view and worst for the VCs. This can be called the F-optimal stable outcome. ${ }^{6}$

\footnotetext{
${ }^{6}$ See Demange and Gale [9] for a complete proof of the above this property.
} 


\section{Conclusion}

In this paper we model a venture capital industry as a two-sided matching game and analyse the set of stable outcomes. We show that when firms need to raise external fund to finance their projects, in equilibrium, the capital-poor firms have to rely on more informed capital in the market. This conforms to the findings of Hölmstrom and Tirole [12], and Repullo and Suárez [20]. Unlike these two works, ours is a model with finite number of individuals and we do not allow for any correlation among the project returns. But the use of matching games to model the financial market allows us endogenise the payoffs of all the participating individuals. We also propose a very simple framework that is able to solve general (competitive) equilibrium models of financial markets characterised by incentive problems. The payoffs of firms with higher wealth are typically higher in equilibrium. It is worth noting that, the results obtained in Proposition 3 are robust to any equilibrium matching patterns. We also show that entry of new venture capitalists with better monitoring capacity does not necessarily enhance total efficiency.

One limitation of the current paper should be recognised. The model we describe here is essentially a static one which fails to capture the dynamic aspects of a venture capital contracting. In a VC-backed firm, the venture capitalists generally finance the project in consecutive stages. The contracts that emerge in a long term relationship, in reality, can be quite different from a standard one-period optimal incentive compatible contracts. Convertible debt (debt contract in the early stages and equity-like contract in the later stages) is the most common in use. Issues regarding stage financing and the analysis of the above mentioned contract form are beyond the scope of this very stylised model. The novelty of the use of a one-period matching game is that it allows us to determine the payoffs endogenously along with the equilibrium matching.

The current model leaves several avenues for future research. We consider a one-to-one matching game with several venture capitalists and several firms. If the project return are correlated then this would call for more sophisticated contract design and a many-to-one matching model, which would not be a trivial extension of the financial market described in the current paper. The equilibrium in the case with correlated projects would then facilitate to analyse the effects of different kinds of macroeconomic shocks. A one-to-one matching model is a simple way to capture the essence of covenants of a new venture that were discussed earlier. Another extension would be to allow more than one VC to invest in the same firm. Often the issue of non-exclusivity of contracts in the credit market bears important consequences on the properties of market equilibria. ${ }^{7}$ Our one-to-one feature essentially implies exclusive contracts. A many-to-one matching set up is able to incorporate the scenario where several venture capitalists with different monitoring capacities invest in the same firm. In this case, as Hölmstrom and Tirole [12] interpret, if a more informed investor monitors the firm then it works as certifying the firm's solvency

\footnotetext{
${ }^{7}$ See Kahn and Mookherjee [18], and Bisin and Guaitoli [5] for analyses of non-exclusive contracts.
} 
and helps attract external capital into the firm from less informed investors. Finally, one can extend the model by making the venture capitalists capital constrained. This would give rise to a moral hazard problem in the level of monitoring, and it would also be more rational then to consider correlated project returns in a many-to-one setup.

\section{References}

[1] Daniel A. Ackerberg and Maristella Botticini. "Endogenous matching and the empirical detarminants of contract form". Journal of Political Economy, 110(3):564-591, 2002 .

[2] Ahmet Alkan and David Gale. "The core of the matching game". Games and Economic Behavior, 2:203-212, 1990.

[3] Garry S. Becker. "A theory of marriage: Part I". Journal of Political Economy, 81(4):813-846, 1973.

[4] Timothy Besley and Maitreesh Ghatak. "Competition and incentives with motivated agents". forthcoming, American Economic Review, 2004.

[5] Alberto Bisin and Danilo Guaitoli. "Moral hazard and non-exclusive contracts". forthcoming, Rand Journal of Economics, 2004.

[6] Jiawei Chen. "Two-sided matching and spread determinants in the loan market: An empirical analysis". Mimeo, 2005.

[7] Vincent P. Crawford and Elsie M. Knoer. "Job matching with heterogeneous firms and workers". Econometrica, 49(2):437-450, March 1981.

[8] Kaniṣka Dam and David Pérez-Castrillo. "The principal-agent matching market". Forthcoming in Frontiers of Theoretical Economics., 2006.

[9] Gabrielle Demange and David Gale. "The strategy structure of two-sided matching markets". Econometrica, 53(4):873-888, July 1985.

[10] Paul Gompers and Josh Lerner. "Optimal investment, monitoring and the staging of venture capital". Journal of Finance, 50:1461-1489, 1995.

[11] Paul Gompers and Josh Lerner. The Venture Capital Cycle. The MIT Press, Cambridge, Massachusetts and London, England, 1999.

[12] Bengt Hölmstrom and Jean Tirole. "Financial intermediation, lonable funds, and the real sector". Querterly Journal of Economics, 112:663-691, August 1997. 
[13] Roman Inderst and Holger M. Müller. "The effect of capital market characteristics on the value of start-up firms". forthcoming, Journal of Financial Economics, 2004.

[14] Steven N. Kaplan and Per Stromberg. "Financial contracting theory meets the real world: An empirical analysis of venture capital contracts". The Review of Economic Studies, 70:1-35, 2002.

[15] Patrick Legros and Andrew F. Newman. "Beauty is a beast, frog is a prince: Assortative matching with nontransferabilities". Revised version of CEPR DP 3462, 2002, February 2004.

[16] Fei Li and Masako Ueda. "CEO-firm match and principal-agent theory". Mimeo, 2005.

[17] Claudio Michelacci and Javier Suárez. "Business creation and the stock market". The Review of Economic Studies, 71:459-481, 2004.

[18] Dilip Mookherjee and Charles M. Kahn. "Competition and incentives with nonexclusive contracts". Rand Journal of Economics, 29:443-465, 1998.

[19] Raghuram G. Rajan. "Insiders and outsiders: The choice between informed and arm's-length debt". Journal of Finance, 47:1367-1400, 1992.

[20] Rafael Repullo and Javier Suárez. "Entrepreneural moral hazard and bank monitoring: A model of the credit channel". European Economic Review, 44:1931-1950, 2000 .

[21] Alvin E. Roth and Marilda Sotomayor. Two-sided matching: A study in gametheoretic modeling and analysis. Cambridge University Press, New York and Melbourne, 1990. Econometric Society Monographs, no. 18.

[22] Konstantinos Serfes. "Risk sharing vs. incentives: Contract design under two-sided heterogeneity". forthcoming, Economics Letters, 2001.

[23] Lloyd Shapley and Martin Shubik. "The assignment game I: the core". International Journal of Game Theory, 1:111-130, 1972.

[24] Robert Shimer and Lones Smith. "Assortative matching and search". Econometrica, 68(2):343-369, 2000.

[25] Morten Sorensen. "How smart is smart money? an empirical two-sided matching model of venture capital". Mimeo, 2005.

\section{Appendix}

\section{A. Analysis of the Optimal Contracts}


We solve for the optimal contract for a VC-firm pair $\left(v_{i}, f_{j}\right)$. The contract should solve the following maximisation programme:

$$
\begin{array}{r}
\max _{\left\{e_{i j}, R_{i j}, r_{i j}\right\}} e_{i j} R_{i j}+\left(1-e_{i j}\right) r_{i j}-m_{i} \\
\text { s.t. } \quad e_{i j}\left(y-R_{i j}\right)-\left(1-e_{i j}\right) r_{i j}+\frac{1-e_{i j}^{2}}{2 m_{i}} \geq s^{j} \\
e_{i j}=m_{i}\left(y-R_{i j}+r_{i j}\right) \\
R_{i j} \leq y+w^{j} \\
r_{i j} \leq w .
\end{array}
$$

Since, constraint (2) is satisfied with equality we can substitute for $R_{i j}$ in the objective function and the other constraints in order to obtain the following reduced programme:

$$
\begin{aligned}
\max _{\left\{e_{i j}, r_{i j}\right\}} e_{i j} y-\frac{e_{i j}^{2}}{m_{i}}+r_{i j} \\
\text { s.t. } \quad \frac{e_{i j}^{2}}{2 m_{i}}-r_{i j}+\frac{1}{2 m_{i}} \geq s^{j} \\
r_{i j} \leq w^{j} .
\end{aligned}
$$

Let $\nu_{1}$ and $\nu_{2}$ be the Lagrange multipliers of the above programme. The Kuhn-Tucker (first-order) conditions are given by:

$$
\begin{aligned}
y-\frac{2 e_{i j}}{m_{i}}+\nu_{1} \frac{e_{i j}}{m_{i}} & =0 \\
1-\nu_{1}-\nu_{2} & =0 \\
\nu_{1}\left(\frac{e_{i j}^{2}}{2 m_{i}}-r_{i j}+\frac{1}{2 m_{i}}-s^{j}\right) & =0 \\
\nu_{2}\left(w^{j}-r_{i j}\right) & =0 \\
\frac{e_{i j}^{2}}{2 m_{i}}-r_{i j}+\frac{1}{2 m_{i}}-s^{j} & \geq 0 \\
w^{j}-r_{i j} & \geq 0 \\
\nu_{1}, \nu_{2} & \geq 0 .
\end{aligned}
$$

We consider the following cases.

CASE 1: $\nu_{1}=\nu_{2}=0$. This is not compatible with equation (8). 
CAsE 2: $\nu_{1}>0$ and $\nu_{2}=0$. This is the first-best situation. Let $\left(e_{i j}^{*}, R_{i j}^{*}, r_{i j}^{*}\right)$ be the candidate solution in this case. Then $e_{i j}^{*}=1$. From constraint $(2)$ in programme $\left(P_{i j}\right)$ and equation (9), one gets

$$
R_{i j}^{*}=r_{i j}^{*}=y-s^{j}
$$

The utilities are given by:

$$
\begin{aligned}
U_{i}^{*} & =y-s^{j}, \\
u_{j}^{*} & =s^{j} .
\end{aligned}
$$

Finally, the solution must satisfy (12), i.e.,

$$
\frac{m_{i} y^{2}}{2}+\frac{1}{2 m_{i}}-s^{j}<w^{j}
$$

Hence, for $\left(v_{i}, f_{j}\right)$ in the above region, $\left(p_{i j}^{*}, R_{i j}^{*}, r_{i j}^{*}\right)$ is candidate for an optimum. In this region, the contract is the first-best contract where the provision of incentive does not involve any cost.

CASE 3: $\nu_{1}=0$ and $\nu_{2}>0$. Then from equation (10), $r_{i j}^{0}=w^{j}$. From equations (8) and (7) we have $e_{i j}^{0}=\frac{m_{i} y}{2}$. Then from constraint (2) of programme $\left(P_{i j}\right)$ we get $R_{i j}^{0}=\frac{y}{2}+w^{j}$. The utilities are given by:

$$
\begin{aligned}
U_{i}^{0} & =\frac{m_{i} y^{2}}{4}+w^{j}, \\
u_{j}^{0} & =\frac{m_{i} y^{2}}{8}+\frac{1}{2 m_{i}}-w^{j} .
\end{aligned}
$$

Finally, the solution must satisfy equation (11) which implies

$$
\frac{m_{i} y^{2}}{8}+\frac{1}{2 m_{i}}-s^{j}>w^{j}
$$

Hence, for $\left(v_{i}, f_{j}\right)$ in the above region, $\left(e_{i j}^{0}, R_{i j}^{0}, r_{i j}^{0}\right)$ is candidate for an optimum.

CASE 4: $\nu_{1}>0$ and $\nu_{2}>0$. Then from (10), $\widehat{r}_{i j}=w^{j}$. Substituting this in equation (9) we get,

$$
\widehat{e}_{i j}=\sqrt{2 m_{i}\left(w^{j}+s^{j}\right)-1} .
$$

Then from constraint (2) of programme $\left(P_{i j}\right)$ we get

$$
\widehat{R}_{i j}=y+w^{j}-\frac{1}{m_{i}} \sqrt{2 m_{i}\left(w^{j}+s^{j}\right)-1} .
$$

The utilities are given by:

$$
\begin{aligned}
& \widehat{U}_{i}=y \sqrt{2 m_{i}\left(w^{j}+s^{j}\right)-1}-2 s^{j}-w^{j}+\frac{1}{m_{i}}, \\
& \widehat{u}_{j}=s^{j} .
\end{aligned}
$$


Since, $\nu_{1}>0$ from equation (7) we have $m_{i} y-2 \widehat{e}_{i j} \leq 0$. This implies

$$
\frac{m_{i} y^{2}}{8}+\frac{1}{2 m_{i}}-s^{j} \leq w^{j}
$$

Also $\nu_{1}<1$ implies that $m_{i} y-\widehat{e}_{i j} \geq 0$ (equation (7)). Hence we get

$$
\frac{m_{i} y^{2}}{2}+\frac{1}{2 m_{i}}-s^{j} \geq w^{j}
$$

Hence, for $\left(v_{i}, f_{j}\right)$ in the above region, $\left(\widehat{e}_{i j}, \widehat{R}_{i j}, \widehat{r}_{i j}\right)$ is candidate for an optimum. Given the previous analysis, we summarise the optimal contracts as follow:

$$
r_{i j}= \begin{cases}y-s^{j}, & \text { if } \frac{m_{i} y^{2}}{2}+\frac{1}{2 m_{i}}-s^{j}<w^{j}, \\ w^{j}, & \text { if } \frac{m_{i} y^{2}}{2}+\frac{1}{2 m_{i}}-s^{j} \geq w^{j} .\end{cases}
$$

and

$$
R_{i j}= \begin{cases}y-s^{j}, & \text { if } \frac{m_{i} y^{2}}{2}+\frac{1}{2 m_{i}}-s^{j}<w^{j}, \\ y+w^{j}-\frac{1}{m_{i}} \sqrt{2 m_{i}\left(w^{j}+s^{j}\right)-1,}, & \text { if } \frac{m_{i} y^{2}}{8}+\frac{1}{2 m_{i}}-s^{j} \leq w^{j} \leq \frac{m_{i} y^{2}}{2}+\frac{1}{2 m_{i}}-s^{j}, \\ \frac{y}{2}+w^{j}, & \text { if } \frac{m_{i} y^{2}}{2}+\frac{1}{2 m_{i}}-s^{j}>w^{j} .\end{cases}
$$

The probability of success (or, effort) is given by:

$$
e_{i j}= \begin{cases}1, & \text { if } \frac{m_{i} y^{2}}{2}+\frac{1}{2 m_{i}}-s^{j}<w^{j}, \\ \sqrt{2 m_{i}\left(w^{j}+s^{j}\right)-1,} & \text { if } \frac{m_{i} y^{2}}{y_{i}}+\frac{1}{2 m_{i}}-s^{j} \leq w^{j} \leq \frac{m_{i} y^{2}}{2}+\frac{1}{2 m_{i}}-s^{j}, \\ \frac{m_{i} y}{2}, & \text { if } \frac{m_{i} y^{2}}{8}+\frac{1}{2 m_{i}}-s^{j}>w^{j} .\end{cases}
$$

\section{B. Proof of Proposition 1}

Suppose $(\mu, U, u)$ is stable, but the contract $c_{i j}$ signed by $v_{i}$ and $f_{j}$, where $\mu\left(f_{j}\right)=v_{i}$, is not Pareto optimal. Then there exists a contract $c_{i j}^{\prime}$, feasible for the pair $\left(v_{i}, f_{j}\right)$ such that (i) $U_{i}\left(f_{j}, c_{i j}^{\prime}\right)>U_{i}\left(f_{j}, c_{i j}\right)$ and (ii) $u_{j}\left(v_{i}, c_{i j}^{\prime}\right)>u_{j}\left(v_{i}, c_{i j}\right)$. In that case $v_{i}$ and $f_{j}$ will block $(\mu, U, u)$ with $c_{i j}^{\prime}$. This is a contradiction.

\section{Proof of Proposition 2}

In order to prove this proposition we introduce the following lemma. This will also be used in subsequent proofs.

Lemma 1 Under moral hazard, if $w^{j}>w^{j^{\prime}}$ and $s^{j} \leq s^{j^{\prime}}$, then $U\left(m_{i}, w^{j}, s^{j}\right)>U\left(m_{i}, w^{j^{\prime}}, s^{j^{\prime}}\right)$ for any venture capitalist $v_{i}$. 
Proof Consider the value function $U\left(m_{i}, w^{j}, s^{j}\right)$ of programme $\left(P_{i j}\right)$. Using Envelope Theorem we get,

$$
\frac{\partial U\left(m_{i}, w^{j}, s^{j}\right)}{\partial w^{j}}=\nu_{2}>0 .
$$

The above implies:

$$
U\left(m_{i}, w^{j}, s^{j}\right)>U\left(m_{i}, w^{j^{\prime}}, s^{j}\right) \quad \text { if } \quad w^{j}>w^{j^{\prime}}
$$

Also

$$
\frac{\partial U\left(m_{i}, w^{j}, s^{j}\right)}{\partial s^{j}}=-\nu_{1}<0,
$$

since, at the (incentive constrained) optimum $\nu_{1}>0$. Hence, we have

$$
U\left(m_{i}, w^{j^{\prime}}, s^{j}\right)>U\left(m_{i}, w^{j^{\prime}}, s^{j^{\prime}}\right) \quad \text { if } s^{j}<s^{j^{\prime}}
$$

The above two together imply:

$$
U\left(m_{i}, w^{j}, s^{j}\right)>U\left(m_{i}, w^{j^{\prime}}, s^{j^{\prime}}\right) \quad \text { if } w^{j}>w^{j^{\prime}} \text { and } s^{j} \leq s^{j^{\prime}} .
$$

This completes the lemma.

It is important to note that under moral hazard the limited liability constraint of the firm $\left(L F_{j}\right)$ is binding. The above result does not hold if the contracts are first-best. Now suppose $w^{j}>w^{j^{\prime}}$ are both matched and in a stable outcome $s^{j^{\prime}} \geq s^{j}$. Let $\mu\left(f_{j}\right)=v_{i}$ and $\mu\left(f_{j^{\prime}}\right)=v_{i^{\prime}}$. By Lemma 1, $U\left(m_{i^{\prime}}, w^{j}, s^{j}\right)>U\left(m_{i^{\prime}}, w^{j^{\prime}}, s^{j^{\prime}}\right)$. Hence, there exists $c_{i^{\prime} j}^{\prime}=c_{i^{\prime} j}\left(s^{j}\right)-\varepsilon$ for $\varepsilon>0$, small enough such that (i) $U_{i^{\prime}}\left(w^{j}, c_{i^{\prime} j}^{\prime}\right)=U\left(m_{i^{\prime}}, w^{j}, s^{j}\right)-\varepsilon>$ $U\left(m_{i^{\prime}}, w^{j^{\prime}}, s^{j^{\prime}}\right)$ and (ii) $u_{j}\left(m_{i^{\prime}}, c_{i^{\prime} j}^{\prime}\right) \geq s^{j}+\varepsilon>s^{j} .{ }^{8}$ Hence, $\left(\mu\left(f_{j^{\prime}}\right)\right.$ and $\left.f_{j}\right)$ would block the outcome with $c_{i^{\prime} j}^{\prime}$, which contradicts the stability of the initial outcome.

The second part follows directly from the fact that if a firm is unmatched then he signs a contract $c^{\text {null }}$. Also note that if a firm $f_{j}$ is matched, then by individual rationality $s^{j} \geq 0$.

\section{Proof of Proposition 3}

Let $l=\min \{n, N\}$. It is easy to see that there cannot be more than $l$ pairs in a stable outcome since the matching game is one-to-one. Suppose that in a stable outcome $(\mu, U, u)$ strictly less than $l$ pairs are formed. Then there must be at least one $\mathrm{VC}$, say $v_{i}$ and one firm, say $f_{j}$ are unmatched, both earing zero payoff. Then there exists a contract $c_{i j}^{\prime}=c_{i j}(0)-\varepsilon$ such that $U_{i}\left(f_{j}, c_{i j}^{\prime}\right)=U\left(m_{i}, w^{j}, 0\right)-\varepsilon>0$ and $u_{j}\left(v_{i}, c_{i j}^{\prime}\right) \geq \varepsilon>0$. Hence, $v_{i}$ and $f_{j}$ block the outcome with $c_{i j}^{\prime}$, which is a contradiction. The above also

\footnotetext{
${ }^{8}$ For any contract, $c_{i j}-\varepsilon=\left(R_{i j}-\varepsilon, r_{i j}-\varepsilon\right)$.
} 
implies that if there are same number of firms and venture capitalists, then there is no firm or no VC remains unmatched.

Suppose there are more firms than venture capitalists $(n>N)$, and in a stable outcome a firm $f_{j}$ with $w^{j}>w^{N}$ is unmatched. This firm gets zero payoff. If $f_{j}$ is unmatched, then there must be some $f_{j^{\prime}}$ with $w^{j^{\prime}} \leq w^{N}$ matched. Let $\mu\left(f_{j^{\prime}}\right)=v_{i^{\prime}}$. Given Proposition $2, s^{j^{\prime}}$ must be equal to zero since $w^{j}>w^{j^{\prime}}$. Then following Lemma 1, there exists a contract $c_{i^{\prime} j}^{\prime}=c_{i^{\prime} j}(0)-\varepsilon$ such that $U_{i^{\prime}}\left(f_{j}, c_{i^{\prime} j}^{\prime}\right)=U\left(m_{i^{\prime}}, w^{j}, 0\right)-\varepsilon>U\left(m_{i^{\prime}}, w^{j^{\prime}}, 0\right)$ and $u_{j}\left(m_{i^{\prime}}, c_{i^{\prime} j}^{\prime}\right) \geq \varepsilon>0$. Thus, $v_{i^{\prime}}$ and $f_{j}$ block the outcome with $c_{i^{\prime} j}^{\prime}$, which is a contradiction. Now suppose that there are more VCs than firms and in a stable outcome a VC $v_{i}$ with $m_{i}>m_{n}$ is unmatched. Then there is some $v_{i^{\prime}}$ with $m_{i^{\prime}} \leq m_{n}$ is matched with some firm, say $f_{j}$. It is easy to check that $U\left(m_{i}, w^{j}, s^{j}\right)>U\left(m_{i^{\prime}}, w^{j}, s^{j}\right)$ since $m_{i}>m_{i^{\prime}}{ }^{9}$ Then there exists a contract $c_{i j}^{\prime}=c_{i j}\left(s^{j}\right)-\varepsilon$ with which $v_{i}$ and $f_{j}$ block the outcome.

\section{E. Proof of Proposition 4}

First we show that in any stable outcome $(\mu, U, u)$ the condition of "Decreasing Willingness to Pay" (DWP) is always satisfied. This condition is given by:

$$
\Delta U_{i}\left(f_{j}, f_{j^{\prime}}\right) \leq \Delta U_{i^{\prime}}\left(f_{j}, f_{j^{\prime}}\right) \text { whenever } m_{i}>m_{i^{\prime}} \text { and } w^{j}>w^{j^{\prime}} .
$$

As we have discussed earlier that the solution to programme $\left(P_{i j}\right)$ is candidate to be optimal over three disjoint regions of the parameter space. It is easy check that under firstbest and when the firm's individual rationality constraint is not binding $\Delta U_{i}\left(f_{j}, f_{j^{\prime}}\right) \leq$ $\Delta U_{i^{\prime}}\left(f_{j}, f_{j^{\prime}}\right)$ for $m_{i}>m_{i^{\prime}}$ and $w^{j}>w^{j^{\prime}}$. So (DWP) is trivially satisfied.

To see this in the intermediate region, consider the maximum value function $U\left(m_{i}, w^{j}, s^{j}\right)$ of the maximisation programme $\left(P_{i j}\right)$. From this we get

$$
\frac{\partial^{2} U}{\partial w^{j} \partial m_{i}}=\frac{\partial^{2} U}{\partial s^{j} \partial m_{i}}=y \sqrt{2 m_{i}\left(w^{j}+s^{j}\right)-1}\left[1-m_{i}\left(w^{j}+s^{j}\right)\left(2 m_{i}\left(w^{j}+s^{j}\right)-1\right)^{-1}\right] \leq 0,
$$

since $\widehat{e}_{i j} \leq 1$. The above equation implies:

$$
\begin{aligned}
U\left(m_{i}, w^{j}, s^{j}\right)-U\left(m_{i^{\prime}}, w^{j}, s^{j}\right) & \leq U\left(m_{i}, w^{j^{\prime}}, s^{j}\right)-U\left(m_{i^{\prime}}, w^{j^{\prime}}, s^{j}\right), \\
U\left(m_{i}, w^{j^{\prime}}, s^{j}\right)-U\left(m_{i^{\prime}}, w^{j^{\prime}}, s^{j}\right) & \leq U\left(m_{i}, w^{j^{\prime}}, s^{j^{\prime}}\right)-U\left(m_{i^{\prime}}, w^{j^{\prime}}, s^{j^{\prime}}\right) .
\end{aligned}
$$

The above two together imply

$$
U\left(m_{i}, w^{j}, s^{j}\right)-U\left(m_{i}, w^{j^{\prime}}, s^{j^{\prime}}\right) \leq U\left(m_{i^{\prime}}, w^{j}, s^{j}\right)-U\left(m_{i^{\prime}}, w^{j^{\prime}}, s^{j^{\prime}}\right) .
$$

\footnotetext{
${ }^{9}$ Consider the value function $U\left(m_{i}, w^{j}, s^{j}\right)$ of programme $\left(\mathrm{P}_{i j}^{\prime}\right)$ in Appendix A. Then $\frac{\partial U}{\partial m_{i}}=$ $\frac{y\left(w^{j}+s^{j}\right)}{\left(2 m_{i}\left(w^{j}+s^{j}\right)-1\right)^{\frac{1}{2}}}-\frac{1}{m_{i}^{2}}$. The above expression is positive under the assumption $m_{i} y \geq 1$. It is obvious that in the other two regions also $U\left(m_{i}, .,.\right)$ is increasing in $m_{i}$.
} 
Next we show that in a stable outcome if the condition (DWP)) holds then the matching is negatively assortative (NAM), i.e., for any $f_{j}, f_{j^{\prime}} \in F$ and $v_{i}, v_{i^{\prime}} \in V$ with $w^{j}>w^{j^{\prime}}$ and $m_{i}>m_{i^{\prime}}$, we have $\mu\left(f_{j}\right)=v_{i^{\prime}}$ and $\mu\left(f_{j^{\prime}}\right)=v_{i}$. Suppose in a stable outcome $(\mu, U, u)$ the above condition holds and $\mu$ is not negatively assortative. Then there exist $f_{j}, f_{j^{\prime}} \in F$ and $v_{i}, v_{i^{\prime}} \in V$ with $w^{j}>w^{j^{\prime}}$ with $w^{j}>w^{j^{\prime}}$ and $m_{i}>m_{i^{\prime}}$ such that $\mu\left(f_{j}\right)=v_{i}$ and $\mu\left(f_{j^{\prime}}\right)=v_{i^{\prime}}$. Since the outcome is stable it must be the case that neither $\left(v_{i}, f_{j^{\prime}}\right)$ nor $\left(v_{i^{\prime}}, f_{j}\right)$ can block the outcome. Hence, we must have (i) $U\left(m_{i}, w^{j}, s^{j}\right) \geq U\left(m_{i}, w^{j^{\prime}}, s^{j^{\prime}}\right)$ and (ii) $U\left(m_{i^{\prime}}, w^{j^{\prime}}, s^{j^{\prime}}\right) \geq U\left(m_{i^{\prime}}, w^{j}, s^{j}\right)$. These two inequalities together imply that $\Delta U_{i}\left(f_{j}, f_{j^{\prime}}\right) \geq \Delta U_{i^{\prime}}\left(f_{j}, f_{j^{\prime}}\right)$, which is a contradiction to (DWP).

\section{F. Proof of Proposition 5}

We have already proven that in a stable outcome the matching is negatively assortative. Take any $f_{j}, f_{j^{\prime}} \in F$ and $v_{i}, v_{i^{\prime}} \in V$ with $w^{j}>w^{j^{\prime}}$ and $m_{i}>m_{i^{\prime}}$. Stability implies that $\mu\left(f_{j}\right)=v_{i^{\prime}}$ and $\mu\left(f_{j^{\prime}}\right)=v_{i}$. If we prove the inequalities for these two pairs, by pairwise comparison these hold for all $l$ pairs. So we show that in a stable outcome $(\mu, U, u)$, one cannot have (i) $\Delta U_{i}\left(f_{j}, f_{j^{\prime}}\right)>s^{j}-s^{j^{\prime}}$ and (ii) $s^{j}-s^{j^{\prime}}>\Delta U_{i^{\prime}}\left(f_{j}, f_{j^{\prime}}\right)$. In (i), notice that the term on the left hand side of the inequality is the willingness to pay of $\mathrm{VC} v_{i}=\mu\left(f_{j^{\prime}}\right)$ for $f_{j}$ against $f_{j^{\prime}}$, and the right hand side is the difference between the utilities obtained by $f_{j}$ and $f_{j^{\prime}}$, the extra (in terms of utilities) $v_{i}=\mu\left(f_{j^{\prime}}\right)$ has to pay if he would have offered the contract $c_{i j}\left(s^{j}\right)$ to $f_{j}$ instead of offering $c_{i j^{\prime}}\left(s^{j^{\prime}}\right)$ to $j^{\prime}$. This implies that $v_{i}=\mu\left(f_{j^{\prime}}\right)$ has an incentive to form a blocking pair together with $f_{j}$. And such a blocking pair is viable since there exists a contract $c_{i j}^{\prime}=c_{i j}\left(s^{j}\right)-\varepsilon$ such that (a) $U_{i}\left(f_{j}, c_{i j}^{\prime}\right)=U\left(m_{i}, w^{j}, s^{j}\right)-\varepsilon>U\left(m_{i}, w^{j^{\prime}}, s^{j^{\prime}}\right)$ and (b) $u_{j}\left(v_{i}, c_{i j}^{\prime}\right) \geq s^{j}+\varepsilon>s^{j}$. This contradicts the supposition that the outcome was initially stable.

For the other part, write (ii) as $s^{j^{\prime}}-s^{j}<-\Delta U_{i^{\prime}}\left(f_{j}, f_{j^{\prime}}\right)=\Delta U_{i^{\prime}}\left(f_{j^{\prime}}, f_{j}\right)$. This expression is similar to that in (i). Hence, it is easy to check that with the contract $c_{i^{\prime} j^{\prime}}^{\prime}=c_{i^{\prime} j^{\prime}}\left(s^{j^{\prime}}\right)-\varepsilon \mathrm{VC} v_{i^{\prime}}=\mu\left(f_{j}\right)$ and firm $f_{j^{\prime}}$ form a blocking pair, which is a contradiction.

G. Existence of a Stable Outcome (Technical and not intended to be published)

In the following proposition we show that the set of stable outcomes of the financial market is non-empty.

Proposition 6 For the financial market with firms and venture capitalists, the set of stable outcomes is non-empty.

We omit a technical proof. In the following discussion, we relate the matching game described in Section 2.3 to the matching games analysed in Alkan and Gale [2], and Crawford and Knoer [7]. Then it is immediate to prove the existence of a stable outcome for the market. 
In the current model, we describe a one-to-one matching game with individuals engaged in trading units of contracts. Our framework can be seen as a generalisation of the assignment game between buyers and sellers described by Shapley and Shubik [23]. In the assignment game, buyers, who own single indivisible objects apiece, are matched with sellers. In this case, an outcome is a matching and a vector of prices for each buyer-seller pair under the matching. In our model, the transactions occur via contracts rather than prices. The analysis of the optimal contract signed by a VC-firm pair immediately reveals, as is typical in the incentive models, that the optimality is not implied by the maximisation of total surplus of a particular pair. In other words, the downward-sloping Pareto frontier $U\left(m_{i}, w^{j}, s^{j}\right)$ of a pair $\left(v_{i}, f_{j}\right)$ is non-linear in the payoff space. From the maximisation problem described earlier (resulting from a non-cooperative game played between a $\mathrm{VC}$ and a firm) one can see that this non-linearity implies imperfect transferability of surplus between the contracting parties. The matching game described in Section 2.3 is an equivalent cooperative game played between firms and venture capitalists. Our game, unlike the assignment game of Shapley and Shubik [23], is characterised by imperfect transferability of surplus (a non-linear Pareto frontier for each matched pair). Given the set of individuals, $V \cup F$, and the Pareto frontier for a matched pair $\left(v_{i}, f_{j}\right)$, the matching game described above is similar to a general game described by Alkan and Gale [2], and the game between firms and workers described by Crawford and Knoer [7]. A proof of the above proposition can be constructed in the same way as the proofs provided in the above mentioned papers, and hence we omit it in order to avoid technicalities. Observe that, the assignment game of Shapley and Shubik [23] is a special case of ours since the Pareto frontier in their game can be written as $U\left(m_{i}, w^{j}, s^{j}\right) \equiv \phi\left(m_{i}, w^{j}\right)-s^{j}$, where VC $v_{i}$ can transfer surplus perfectly to firm $f_{j}$. 